Article

\title{
From User to Provider: Switching Over in the Collaborative Economy
}

\author{
Myriam Ertz ${ }^{1, *(\mathbb{C}}$, Jonathan Deschênes ${ }^{2}$ and Emine Sarigöllü ${ }^{3}$ (D) \\ 1 LaboNFC, Department of Economics and Administrative sciences, University of Quebec, \\ Saguenay, QC G7H 2B1, Canada \\ 2 Department of Marketing, HEC Montreal, Montreal, QC H3T 2A7, Canada; jonathan.deschenes@hec.ca \\ 3 LaboNFC, Desautels Faculty of Management, McGill University, Montreal, QC H3A 1G5, Canada; \\ emine.sarigollu@mcgill.ca \\ * Correspondence: Myriam_Ertz@uqac.ca; Tel.: +1-418-545-5011
}

Citation: Ertz, M.; Deschênes, J.; Sarigöllü, E. From User to Provider: Switching Over in the Collaborative Economy. Sustainability 2021, 13, 5662 https://doi.org/10.3390/

su13105662

Academic Editor: Renee Wever

Received: 21 April 2021

Accepted: 17 May 2021

Published: 18 May 2021

Publisher's Note: MDPI stays neutral with regard to jurisdictional claims in published maps and institutional affiliations.

Copyright: (C) 2021 by the authors. Licensee MDPI, Basel, Switzerland. This article is an open access article distributed under the terms and conditions of the Creative Commons Attribution (CC BY) license (https:/ / creativecommons.org/licenses/by/ $4.0 /)$.

\begin{abstract}
The collaborative economy comprises resource circulation systems where consumers can act as both obtainers and providers of products and services. Despite considerable research on collaborative economies, there is a dearth of understanding of how individuals switch from being an obtainer to a provider. We address this void in the literature. The objective of this paper is to conceptually introduce and empirically substantiate the switchover concept, which occurs when an individual switches from a user role to a provider one-drawing on 31 in-depth semi-structured interviews with collaborative economy obtainers. The findings suggest that personal values, learning experience, social benefits, mutuality, and peer influence drive obtainers to become providers. In contrast, distrusting strangers, a sense of intimacy, a lack of resources to share, and a lack of skills inhibit the switchover process. Our findings contextualize the drivers and inhibitors idiosyncratically to convert obtainers into providers, offer important implications for managers, contribute to the collaborative economy and sharing economy literature and suggest compelling avenues for future research.
\end{abstract}

Keywords: collaborative economy; sharing economy; switchover; obtainer; provider; values; learning; mutuality; exploratory research

\section{Introduction}

A vital feature of the collaborative economy (CE) is that consumers can participate as obtainers (users) and/or providers. This reality is emphasized in the definition of the $\mathrm{CE}$ as "the set of resource circulation systems which enable consumers to both obtain and provide temporarily or permanently, valuable resources or services through direct interaction with other consumers or through a mediator" [1] (p. 7). Some researchers have more broadly labeled this as an "interchangeability of roles" [2] commonly recognized in the CE literature [1,3-7]. However, while past research has explored factors motivating either users or providers, it lacks a study of factors underlying the "switchover" process, that is, the switch from one role to the other. This paper addresses this void.

Adapting the definition of "switchover" [8] to the context of CE and in line with Scaraboto [9] and Kumar et al. [5], we define switchover as a reversible role transition between user and provider. The current study focuses on switchover specifically from user to provider, which has significant economic, strategic, and sustainability implications.

The user-to-provider switch is of importance to CE managers and developers. Although role interchangeability is a vital characteristic of the $C E$, evidence points to much fewer providers than obtainers $[10,11]$, particularly in tech-mediated CE systems where the provider churn rate is abnormally high $[12,13]$. This problem is particularly acute in what is known as "commercial sharing" [14], since flagship platforms such as Uber, Lyft, or Airbnb struggle to retain their providers. For example, past studies revealed that only 
10 percent of Lyft drivers are still driving for the platform a year later, while for Uber, this proportion plummets to 4 percent [15]. Likewise, there is substantial churn in Airbnb among individual hosts, since over a third of the listings on the site tend to disappear five months later [16]. According to the same study, individuals tend to put a property on the website, welcome a handful of guests, and then remove the property from the website again.

Therefore, it is more difficult for managers to recruit providers, although providers are crucial to the success of the $\mathrm{CE}$ as they are 3.5 times more impactful than obtainers in driving growth $[17,18]$. CE managers should recruit and retain providers rather than obtainers [10,11]. Thus, effective recruitment and maintenance of providers lie at the center of CE success. Understanding the "user-to-provider" switch (hereafter, "switchover") offers managers an opportunity to deploy their resources efficiently and effectively by converting existing users into providers rather than focusing extensively on recruiting new providers.

Prompting switchover is also increasingly crucial for conventional retailers, particularly given the boom of reverse logistics (e.g., reconditioning, refurbishing, restoring, renovating, or repairing products). Increasingly, managers will need to know how to nudge regular consumers to co-create value by providing products and services, which is both strategic and sustainable, as it contributes to circular consumption and, by extension, to the circular economy. Strategically, it is established that maintaining and growing current customers is more resource-efficient than recruiting new ones [19]. Along the same lines, converting current users into providers, rather than (or in addition) to recruiting new providers, is likely to be more profitable. In fact, since it costs an average of five to 25 times more to recruit a new customer versus retain an existing one [20,21], it might be more cost-effective to convert existing users to a provider role. Provision is also sustainable, especially if it concerns tangible goods, since goods are thus granted multiple lives and diverted from landfill. Besides, services provided by individuals may enable broader access for under-privileged or remotely located populations.

The switchover feature has been identified as a critical condition for improved sustainability performance in the CE [7]. Therefore, facilitating the switch from user to providerwhich is typically more challenging than the switch from provider to user-is equivalent to making the CE more sustainable. Managerial action will thus be able to modulate critical variables to improve switchover processes and contribute, at least partially, to address the issue of CE unsustainability that has been well-documented in the literature [22].

Despite its essential implications, switching over remains unexplored in the CE. Therefore, to address this theoretically and managerially relevant gap, the overall objective of the current study is to conceptually introduce and empirically substantiate the switchover concept occurring when an individual switches from a user role to a provider one. To this end, the study pursues the following two specific objectives:

1. Defining and conceptualizing switchover and contextualizing it within the sphere of the collaborative economy;

2. Identifying the factors leading to switchover from user to provider in the collaborative economy.

This study provides researchers, managers, and policymakers with valuable insights into the switchover process. As such, it contributes to the literature on three different fronts. In contrast to past research which focuses on specific $C E$ systems (e.g., specific alternative markets), this study takes a different approach by studying the switchover process in the $\mathrm{CE}$, regardless of exchange type (i.e., swapping, access, secondhand marketplaces, donating), modality (i.e., permanent and temporary), channel (i.e., offline, online, both), or compensation (i.e., none, money, other). Besides, past studies examined drivers to use and provision separately, without connecting them meaningfully to understand user-toprovider transition, despite the cruciality of such knowledge for collaborative platforms. While the drivers of both facets of exchange may indeed differ, this study acknowledges the interchangeability of roles as a critical defining principle of the $C E$ and, as such, focuses 
on the process that enables that interchangeability: the switchover process. Third, the study further focuses on a specific switchover form, from user to provider, given its critical nature for growing and sustaining CE platforms. Finally, this study focuses on the millennial generation (18-33 years old). Although this might limit the generalization of the results, this group is of particular interest due to its lower level of resources to share and comparatively lower experience in collaborative systems as compared to more senior segments of the population. Therefore, they are more likely to be first-time providers. In addition, the switch might be more easily actionable for them, as they face fewer restrictions (e.g., family, work), are open to new experiences, and are comparatively more tech-savvy than other generations [23]. Therefore, millennials appear to be the primary enablers of the CE and the actors of tomorrow's economy. They need to be crucially investigated, and this study answers that imperative by focusing exclusively on millennials.

\section{Research Background}

The term "collaborative" subsumes both notions of mutualization and redistribution. Firstly, the CE allows for the mutualization of any resource (e.g., goods, space, skills, money). Mutualization is defined as a temporary transfer of usage (but not ownership) of good or temporary access to a resource or service [3,24]. It includes diverse practices such as lending, leasing, pooling, and sharing [25]. Secondly, the CE also involves the redistribution of goods, which is the permanent transfer of goods from someone who does not want them to someone who does through secondhand marketplaces, swapping, or donating [11].

Whether in mutualization or redistribution, users are generally more numerous than providers. This observation remains true even with the rise of digital platforms through which newer forms of collaborative exchange have boomed [26]. For example, Poshmark is a variant of classic consignment shops in which the buyer and the seller connect directly to coordinate and perform a transaction [27]. More unique to the digital realm, Facebook's Branded Buy Sell Trade (BST) groups enable individuals to buy and sell products that are restricted by specific brands without any transaction fee or mediation [28]. All these updated and new forms of collaborative exchange increase users' likelihood to switch from user to provider in a mesh-like [29] or rhizomatic system [30].

Past research demonstrated that users are influenced chiefly by utilitarian and especially economic motives, whereas a broader set of non-utilitarian drivers spur on providers [14,31-35]. Utilitarian motives such as profit-making, decluttering, or circumventing the burden of ownership dominate, especially reselling, fee-based renting, or swapping [34-37], but other essential motives are also useful, such as waste avoidance [36,38], social motives (i.e., exchanging with others) [32], community building [31-35], emotional motives [39], or variety seeking [35].

The community-building aspect has been mainly discussed in past research. For example, toy libraries enable parents to educate young children on citizenship within a democracy [32], whereas time banks provide human, social, and cultural capital to their members conducive to fostering strong communities [31]. Although community formation around collaborative exchanges might also prove challenging at times, Philip et al. [35] emphasize the founding elements of community building in collaborative settings, including meaning via gratifying transactions and the co-creation of shared norms that apply as rules within the community. More generally, collaborative exchanges empower consumers, and for people in isolated social situations, they are a good opportunity to build interpersonal relationships [34]. Although the propensity for community engagement may be tempered in contractual or commercial types of collaborative exchanges, it remains a core aspect of many collaborative systems.

Research to identify provider motives has grown over the last decade in various contexts, including alternative marketplaces, such as Really Really Free Markets [40], peer-topeer (P2P) rentals [41], or clothing libraries [42], and even in cross-cultural contexts [43,44]. Achievement motives (i.e., achieving something useful and enacting self-actualization) 
are essential for providers [31,32,39]. Moreover, some symbolically oriented motives were found to be useful, such as immortalizing material objects [35,45]; or engaging in a transforming political act [32]. Although such motives prevail in non-profit forms of collaborative exchanges such as time-banking [31], donating, or toy libraries [32], some also underlie reselling [36,39], swapping, and P2P renting [33-35]. Those purpose-driven motives are complemented with value-laden ones, including showing altruistic values and behavior $[31,34,35]$ and acting upon a sense of reciprocity [33,34].

Therefore, past research has produced substantial knowledge about factors that trigger either use or provision in the $\mathrm{CE}$, albeit creating de facto separation between the two roles given their examination in a silo. Nonetheless, the literature, summarized in Table 1, provides partial insight into the user-provider switchover.

Table 1. Summary of past research in the collaborative economy.

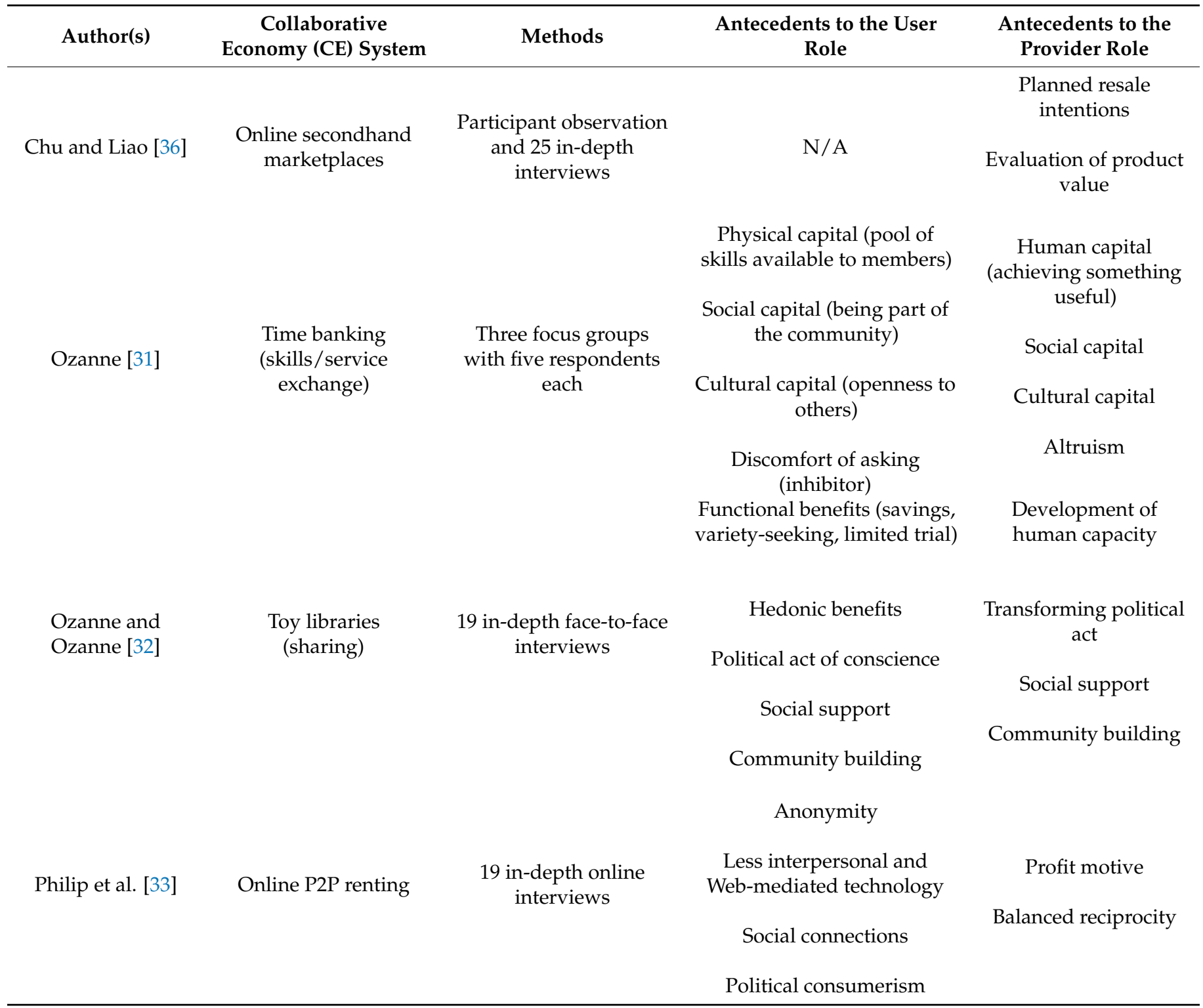


Table 1. Cont.

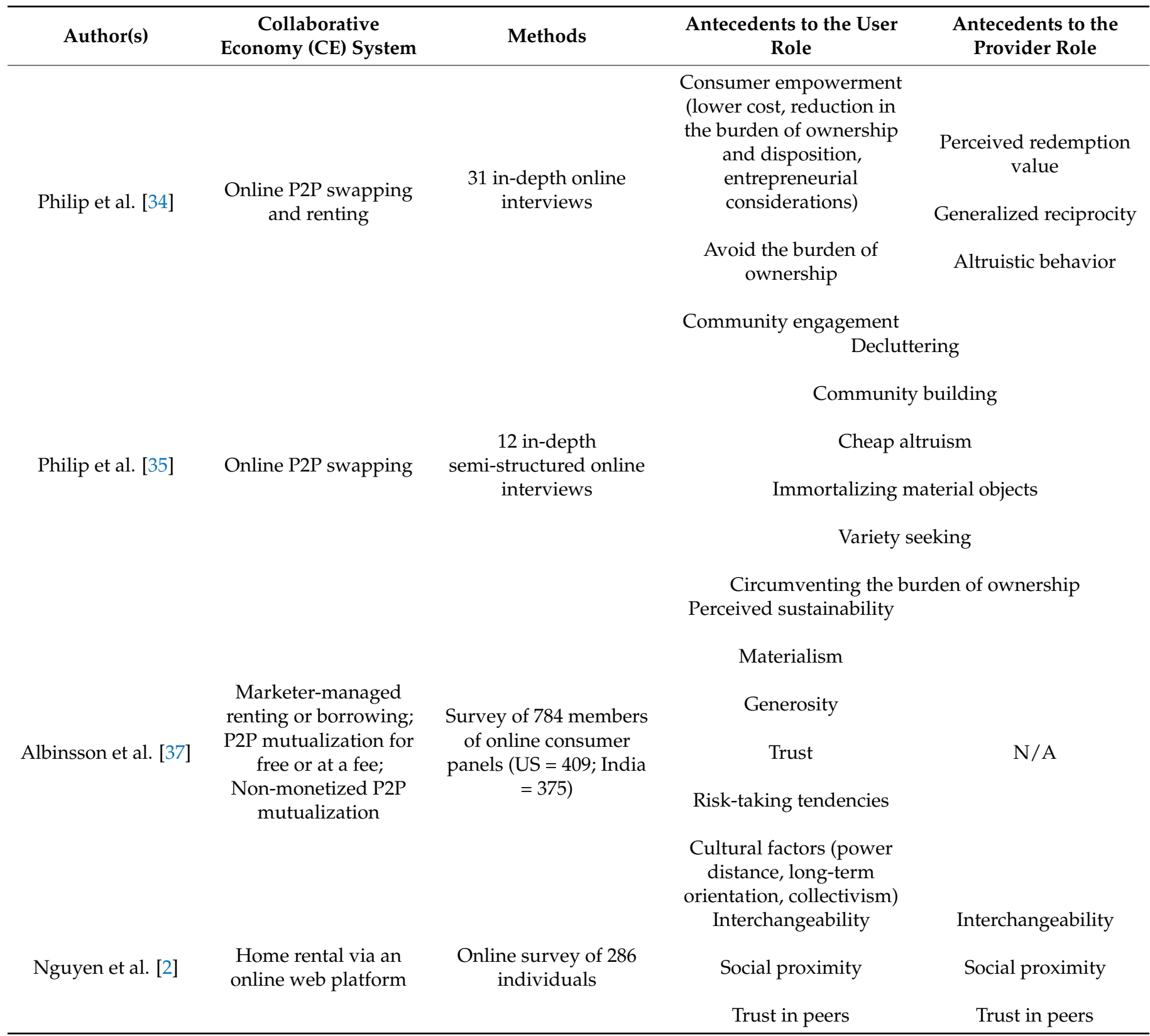

Although motives to acquire (i.e., use) and to dispose of (i.e., provide) objects within the $\mathrm{CE}$ are shown to be congruent [3], the process underlying the transition from user to provider remains unclear. Users might be deterred from becoming providers for various reasons, such as expectancy of more effort, perception of more privacy or process risk, and belief of independence through ownership instead of redistributing or mutualizing objects [41]. Besides, while users are primarily driven by value and convenience, providers also seem impelled by symbolic or idealistic motives, as mentioned earlier [31,33-35]. Despite strategic advantages emerging from the conversion of users into providers [17,18], there is a lack of research on the process that governs this transition.

The work that comes closest to studying the switchover process so far is Philip et al.,'s $[33,36]$ research on online peer-to-peer renting and swapping. They provided a typology of participants by classifying them as either one-way users (i.e., users only or providers only), two-way users (i.e., those who use and provide), or non-users $[33,36]$. While these studies offer insights 
about factors that may influence non-users to become users, neither examines the drivers' particularities that lead users to become providers.

In another relevant study, Albinsson et al. [37] identified what drives non-users to become users. They found that perceived sustainability, materialism, generosity, trust, risk-taking tendencies, and cultural factors play a role in that process. They further drew on Philip et al.,'s $[33,34]$ studies to differentiate between one-way and two-way users, but without identifying the process that underlies the transition from one-way to two-way users or from a one-way user to a one-way provider. Furthermore, other researchers [2] proposed that the interchangeability feature fosters participation intentions, either as a user or as a provider, or both. In summary, the literature offers emerging themes and theoretical foundations for further research in the user-provider switchover process. We seek to delve deeper into that process by identifying key variables that motivate the transition from user to provider.

\section{Methods}

Using data from informants who participate in the $C E$, this study identified the factors that explain the switchover from user to provider. As initial insights on new topics are typically impossible or challenging to obtain through quantitative research methods [46], we opted for an exploratory research design consisting of in-depth interviews.

\subsection{Sample and Data Collection}

Students at a French-speaking university in Quebec, Canada, were recruited using a combination of snowball sampling, convenience sampling, and purposive sampling. Snowball sampling involved recruiting a few respondents and asking each respondent to recruit additional respondents. Convenience sampling consisted of recruiting respondents that were easily accessible to the research team, namely students on the campus or online via an announcement posted on a Facebook student group. Finally, purposive sampling consisted of more targeted respondent selection by recruiting respondents who were knowingly involved in collaborative exchanges. We recruited those in special interest groups such as Facebook's Branded Buy Sell Trade (BST) groups [28]. Three criteria were implemented to select participants: (1) belong to the millennial generation (18-33 years old) because this cohort is the most active in the CE [47]; and (2) have previously both obtained and provided goods or services; or, (3) have previously obtained only, but not provided, to identify impediments for the switchover to provision. During the recruitment process, researchers sought to attain some diversity in terms of age, sex, and citizenship [48]. The final sample consisted of 31 participants (see Table 2).

Table 2. Informants of in-depth interviews.

\begin{tabular}{cccc}
$\begin{array}{c}\text { Informant } \\
\text { ID }\end{array}$ & Alias & Sex & Behaviors \\
\hline 01 & Justine & F & Obtainer (buy online, carpooling, Airbnb)/Provider (gift, \\
online reselling)
\end{tabular}


Table 2. Cont.

\begin{tabular}{|c|c|c|c|}
\hline $\begin{array}{l}\text { Informant } \\
\text { ID }\end{array}$ & Alias & Sex & Behaviors \\
\hline 08 & Armand & M & $\begin{array}{c}\text { Obtainer (carpooling, Blablacar)/Provider (sell online, } \\
\text { Leboncoin, carpooling) }\end{array}$ \\
\hline 09 & Etienne & M & $\begin{array}{l}\text { Obtainer (buy online and offline)/ Provider (sell to friend } \\
\text { and on Facebook group) }\end{array}$ \\
\hline 10 & Fabiola & $\mathrm{F}$ & Obtainer/Provider (buy and sell online, Leboncoin, Vinted) \\
\hline 11 & Adel & $\mathrm{F}$ & $\begin{array}{l}\text { Obtainer/Provider (buy and sell online via Leboncoin, } \\
\text { carpooling via Blablacar, Airbnb) }\end{array}$ \\
\hline 12 & Catherine & $\mathrm{F}$ & $\begin{array}{l}\text { Obtainer/Provider (buy and sell online via Vinted, } \\
\text { carpooling via Blablacar and directly, Airbnb) }\end{array}$ \\
\hline 13 & Sylvestre & M & Obtainer/Provider (crowdfunding, giving, renting) \\
\hline 14 & Helen & $\mathrm{F}$ & $\begin{array}{l}\text { Obtainer/Provider (Couchsurfing, Airbnb, buying and } \\
\text { selling online) }\end{array}$ \\
\hline 15 & Kevin & M & $\begin{array}{c}\text { Obtainer/Provider (loans, Airbnb, carpooling via Facebook, } \\
\text { giving) }\end{array}$ \\
\hline 16 & Naomy & $\mathrm{F}$ & $\begin{array}{l}\text { Obtainer/Provider (carpooling via Amigo Express and } \\
\text { Facebook, buying and selling online }\end{array}$ \\
\hline 17 & Fabien & M & $\begin{array}{c}\text { Obtainer/Provider (buying and selling via Facebook, Kijiji, } \\
\text { giving, Airbnb) }\end{array}$ \\
\hline 18 & Erika & $\mathrm{F}$ & $\begin{array}{c}\text { Obtainer/Provider (buying and selling via Kijiji Marketplace, } \\
\text { carpooling via Facebook) }\end{array}$ \\
\hline 19 & Antoine & M & $\begin{array}{l}\text { Obtainer/Provider (Airbnb, Uber as obtainer, Giving, } \\
\text { renting cars, buying and selling via Kijiji Marketplace) }\end{array}$ \\
\hline 20 & Laurence & $\mathrm{F}$ & $\begin{array}{l}\text { Obtainer/Provider (buying and selling via Facebook and } \\
\text { Vinted) }\end{array}$ \\
\hline 21 & Oliver & M & Obtainer (gift, Airbnb, Uber, buy online) \\
\hline 22 & John & M & $\begin{array}{c}\text { Obtainer (gift, carpooling online with Blablacar, Amigo } \\
\text { Express, Airbnb) }\end{array}$ \\
\hline 23 & Gerard & M & $\begin{array}{c}\text { Obtainer (Carpooling, accommodation services, Blablacar, } \\
\text { Amigo Express, Couchsurfing) }\end{array}$ \\
\hline 24 & Amber & M & Obtainer (gift, Airbnb) \\
\hline 25 & Chantal & $\mathrm{F}$ & Obtainer (Airbnb, carpooling) \\
\hline 26 & Paul & M & Obtainer (buy online, Kijiji) \\
\hline 27 & Elody & $\mathrm{F}$ & Obtainer (Airbnb, carpool, thrift store) \\
\hline 28 & Nicolas & M & $\begin{array}{c}\text { Obtainer (gift, Carpool, Couchsurfing, Airbnb, } \\
\text { crowdfunding) }\end{array}$ \\
\hline 29 & Lucy & $\mathrm{F}$ & Obtainer (carpooling, buy online, Kijiji) \\
\hline 30 & Claire & $\mathrm{F}$ & Obtainer (carpooling Amigo Express and Facebook group) \\
\hline 31 & Florence & $\mathrm{F}$ & $\begin{array}{c}\text { Obtainer (carpooling and buy online via Amigo Express and } \\
\text { Facebook) }\end{array}$ \\
\hline
\end{tabular}

Notes: $\mathrm{F}=$ Female, $\mathrm{M}=$ Male.

The interview guide was written in French, the interviews and analyses were conducted in French, and the results were then translated into English. The interviews were conducted face-to-face by two research assistants and one of the authors who also trained them. All of the interviews were conducted on the university campus. The interviews ensured depth, while the relatively large sample size provided breadth to contribute to information-rich data generation [48]. The interviews lasted between 30 and $60 \mathrm{~min}$ and 
were all audiotaped. During the interviews, participants read a CE definition and critical terms such as redistribution and mutualization. Each informant received a CAD 25 gift card as compensation for their participation.

Informants were asked to (1) state most, and least liked collaborative practices as an ice-breaker; (2) discuss how they started with an obtainer role (such as; secondhand purchase, reception of donation, borrowing a product for free or at a fee, accessing a collaborative service such as Airbnb and Uber/car-sharing). Questions and probes used included; "Have you ever bought a product from another individual/consumer? How (online, offline)? How did it start? Why did you buy secondhand?"; (3) discuss whether they ever acted as a provider role (reselling, donating, lending a product for free or at a fee, providing a collaborative service such as Airbnb and Uber/car-sharing). Questions and probes used included; "Have you ever resold a product to another individual/consumer? How (online, offline)? How did it start? Why did you resell?" If they acted as a provider: (4) to describe how they switched from one role to another or had never been a provider, elaborate on how they see themselves as providers and their impressions about provider behavior. The interviews were conducted in French but were translated to English for this article.

\subsection{Data Analysis}

The data analysis was conducted in six steps [49].

First, the interviews were entirely transcribed, resulting in verbatim transcripts used as input for the qualitative analysis. The respondents were also anonymized at this point.

Second, a pre-analysis of the data (i.e., floating reading) gradually allowed the research team to become familiar with their content. At this step, it was also assessed whether the data were sufficient to answer the research question. Important aspects of the data were also already highlighted at this point.

Third, a thematic text analysis technique using a data matrix was applied to the data set. The data matrix takes the form of a table. It crosses questions on the interview guide by informants to provide each informant's answer to each question in the interview guide to facilitate comparisons and analyses. The research assistants were in charge of this classification work, under the supervision of the same author who supervised the data collection process. Thanks to the data matrix, the transcribed verbatim about a specific question on the discussion guide was analyzed across all 31 participants and summarized into a synthesis. This resulted in a total of 168 pages containing 22,653 words to study. Thematic analysis has the advantage of offering an accessible and theoretically flexible approach to analyzing qualitative data [50]. Most importantly, the thematic analysis provided preliminary insights into raw data and provided researchers with a first overview and general feeling about informants' responses by question.

The fourth stage of the analysis consisted of coding. Coding was developed using open, axial, and selective coding [46] to let the codes emerge, structure them, and further confirm the analysis. This approach helped to unveil relevant themes linked to the objective of the current research and reveal new ones. At the end of the thematic analysis, the authors frequently iterated between qualitative data and theory to probe the patterns that materialized from the qualitative data.

Fifth, by developing categories and establishing themes, the researchers tried to grasp the connections between various aspects of the respondents' situation. Here, the objective was to find confirmations and/or explanations for different relationships identified between specific categories. To this end, we moved back and forth between themes, categories, and possible models of confirmation or explanation, such as, for example, Dolan and Galizzi's [51] theory on behavioral spillovers, where one behavior can significantly affect other behaviors.

Sixth, the interpretation and analysis of qualitative data occurred simultaneously in a back-and-forth process. Interpretation occurred as the research team became immersed in the content of the data, categories, and codes. Interpretation went beyond simply 
describing the data and attributed meaning and consistency to themes, categories, and conceptual models. This final step involved extracting and articulating meanings to explain the data presented, identifying patterns and detecting trends right from the data collection, making sense of what was found in the data, making sense of the results, providing explanations, and drawing conclusions. Checking the findings for their plausibility, rigor, and confirmation is also included.

\section{Results}

The main factors for switching from user to provider are personal values, learning to switch, and experiencing the social dimensions of the CE. Moreover, several inhibitors of switching were identified; distrust in strangers, a sense of intimacy, perceived lack of skills, and lack of resources to share. The next section details these findings. Figure 1 summarizes the themes and sub-themes that emerged from the analysis. Additional supportive verbatim quotes for each identified theme are provided in the Appendix A.

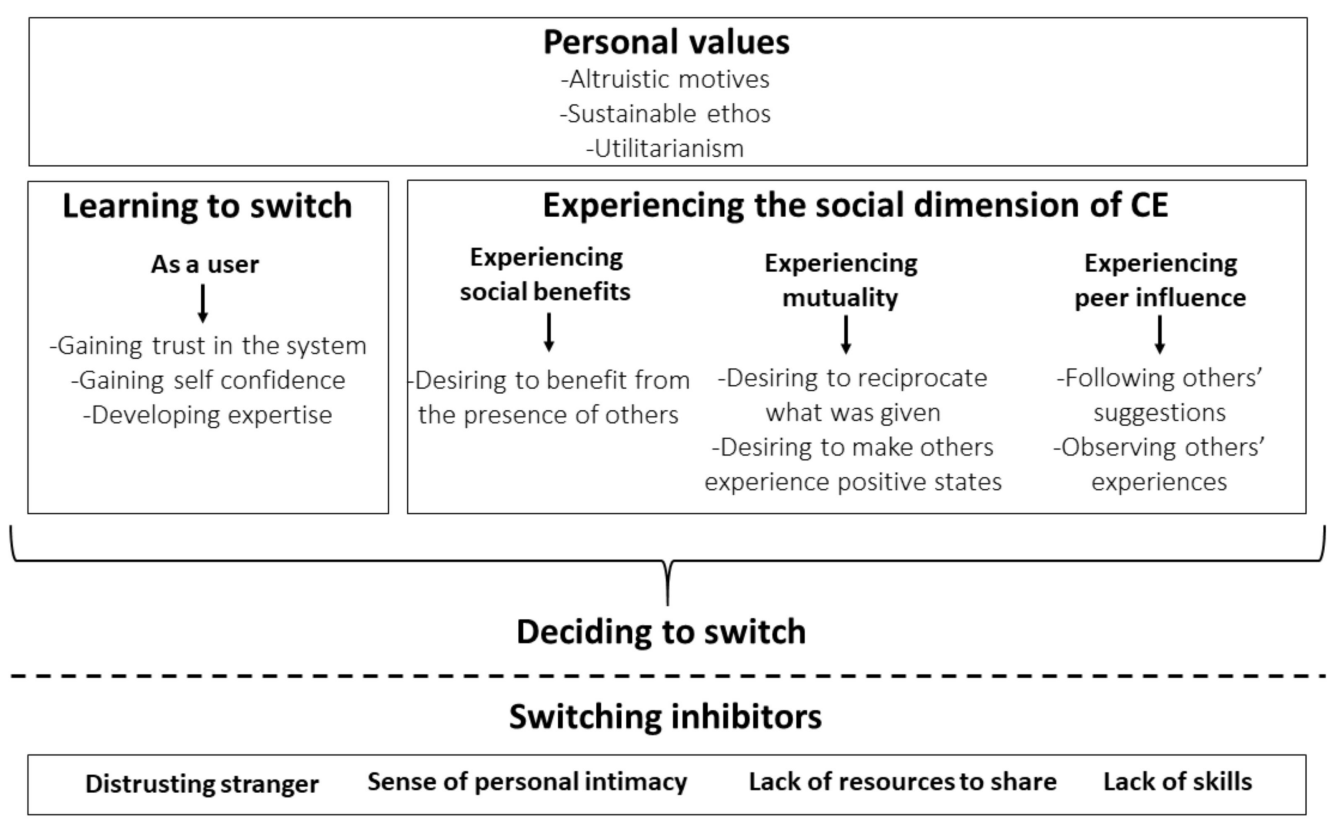

Figure 1. The inductive model of switchover.

These factors will have varying intensity and salience depending on the CE system, exchange type, and product or service involved in the transaction. As for the CE system and exchange type, differentiated levels of trust, mutuality, and personal values are needed for second-hand markets with compensation transactions compared to gift-giving or swapping markets. Likewise, regarding the product or service involved in the exchange, the level of personal involvement will be much lower in the case of a book in contrast to a car. Some key factors such as trust in the CE platform or the business model will be of higher importance to induce the switch when a car is involved than a book. Therefore, this model bears generalizability, since it is a generic framework that comprehensively encompasses various factors that may have differential levels of importance across CE systems, exchange types, and products and services involved in the exchange.

\subsection{Personal Values}

Values comprise principles of life that are personal to an individual and that guide their actions [51]. Personal values were the primary rationale for several informants to switchover in the CE. Particularly, altruistic values originating from sociocultural spheres, such as family, relatives and culture were mentioned, as Barbara stated: 
"It is like a habit for me to share with those who are in need, to help them (about gift). In the society in which I grew up, it is in our culture to give, to help, and share with the poorest, and so it is to avoid waste." (Barbara)

Like other informants, Barbara grew up in an environment that fostered strong habits of helping, sharing, and giving. She is generally motivated by a sense of "doing some good and making others happy." These altruistic values, originating from culture and family about sharing, allowed participants to enjoy benefits as obtainers and later as providers. Therefore, it was natural for some informants to shift from one role to another to sustain these values.

Additionally, because the CE is a way to express sustainability [40], informants with an ecological inclination consider the $\mathrm{CE}$ as a means to act upon their ecological values. Françoise captured this aspect:

"I began by buying at a garage sale, and then I understood what is at stake ... And I sell too when I have something which I do not need anymore, either I sell it, or I give it to other people, to give it a second life. Never throw away if it is still useful because I know that it will pollute our environment, so why not make it useful to another person." (Françoise)

Françoise reveals that experiencing the CE as a buyer was likely to trigger her environmental consciousness. Giving things a second life became a preoccupation for her. Providing, on top of acquiring, is seen as a logical way to reduce the environmental impact of the disposal of goods. When asked what the profile of a CE consumer would be, she added that this person would be adept at minimalism and would be moved by a desire to help others and the planet. Environmental consciousness is therefore clearly present in her view.

In addition to the values expressed above, a tendency for utilitarianism also emerged from responses. For example, the importance of monetary savings was emphasized by various informants. As Antoine puts it: "if I can save money out of such behaviors, I may as well make some money out of it." Monetary incentives remain confined to money-based exchanges such as secondhand purchases. Still, other utilitarian gains such as decluttering or accessibility also constitute utilitarian advantages as it enables individuals to make room for new or more desirable possessions [42].

In some cases, the disposal may also be convenient and save the provider complex waste management hurdles, especially if the obtainer puts in the effort. For example, when an individual gives away clothes in a bin or gives them away to a secondhand shop, the staff of the secondhand organization takes care of restoring and redistributing those clothes. Likewise, an individual may give away or resell furniture on a social network (e.g., Facebook Marketplace). In such instances, the obtainer would ensure the transportation and the reuse of the object. The switchover process may appear highly desirable from a utilitarian point of view by freeing space and new possessions and often appearing as a handy solution to avoid waste management hurdles.

In sum, users may switch to providers due to altruistic motives learned and nurtured through family and culture. Users may also make the switch due to their perception of providing others to foster their sustainability ethos. Finally, providing goods or services to others is also a means to fulfill various utilitarian objectives, such as financial gains in money-based exchanges and decluttering, making space, or easily getting rid of things.

\subsection{Learning to Switch}

Several informants emphasized that their first experience as users empowered them to adopt a provider role. An initial collaborative behavior familiarizes users with how the system works, and habits may develop over time. Most respondents started as obtainers, which is usually perceived as being easier than being a provider. To quote Pierre, "first you buy, then you sell. It's easier that way." Most importantly, in addition to perceiving buying as easier than selling, respondents explained that they discovered the ease of provision 
through their usage activities. As Adel pointed out: "if it works in one way, it should work the other way too." So, successful buying experiences can trigger switchover to provision, as mentioned by Helen:

"I began by buying to test the system because it is easier to buy than sell for me, and I saw that it was not complicated, so now that I know how the systems works, I decided to make the jump, to become a seller." (Helen)

Understanding "how the system works" can help boost one's self-confidence and one's feeling of reassurance and therefore help to initiate the desire to provide goods. As summed up by Oliver:

"When I sell, I reassure the customer since I have already been in their shoes, I use my experience as a buyer to make it easier for my customers. When I am a supplier, the past purchase experience allowed me to gain the confidence to offer stuff myself. If I were not satisfied the first time [as a user], I would not have offered things after that." (Oliver)

Our informants also indicated that CE web platforms could be significant in building their confidence and ease their decision to become providers. As mentioned by Vincent: "Initially, we buy and through the act of purchase we check the reliability of the site and then we can go on with selling." Indeed, as buyers, they take the opportunity to test the reliability of the platforms. Adel confirms this idea: "I will try first as a consumer on this web platform, and if it is well and if the system runs well and I have some good feedback, I'll try then as a provider."

Finally, on top of a sense of confidence and reassurance, the practical experience as a user can also offer valuable knowledge on the potential practice of supplying. For instance, it is while buying secondhand books that Oliver realized that selling was even a possibility. Various informants have expressed a specific transfer of expertise that operates during their user experience. Through positive and negative experiences as a user, one learns to "develop one's model, to adapt", to quote Barbara. As Françoise also mentioned:

"Now I know about all the specificities of the service, and I am ready to offer it [... ] the experience as a consumer may have influenced my tendency to sell later. The purchase has shown that it is easy to sell things without getting in touch, that we can sell all kinds of things and that in this case, it is rather the customers who come to the seller and not the other way around." (Françoise)

Therefore, for Françoise, buying allowed her to gain insights into selling, which helped her choose to switch.

\subsection{Experiencing the Social Dimension of CE}

The CE inherently implies a sense of sociability. Mutualization and redistribution, the two core mechanisms of $\mathrm{CE}$ that we explained above, require individuals and groups to interact and engage together in levels that can create meaningful social bonds [52]. This social dimension can become a motivating factor for becoming a provider. From our data, we derived three aspects of this socialization that can trigger a switch to becoming a provider: the experience of social benefits, mutuality, and peer influence.

Experiencing social benefits. Our findings suggest that obtainers tend to switch roles when they perceive substantial social benefits. This motive has come up in the collaborative systems literature. Such systems are used for utilitarian purposes and for the nexus of social benefits that they typically entail with fellow individuals [1,53]. In extant research, these motives were supported in the theme of the social benefits that captures our informants' perceived importance of social gains brought by the CE. Informants appreciate the opportunity to interact meaningfully with others. The perceived importance of social benefits as a user could trigger the desire to be a provider and anticipation of similar subsequent benefits. As Catherine declared: 
"It's helped me a lot when I did not have a car...so I decided to offer the service when I bought my car because it is socially interesting. I met new persons and friends ...it helps me a lot, so it is a pleasure for me to offer the service." (Catherine)

Fabiola, another respondent, explained how switchover intentions started to emerge following a pleasant experience as an obtainer:

"I started by using, I loved it. So, when I got my car, I was interested in offering the service myself because it gives me companions with whom to travel." (Fabiola)

From Catherine and Fabiola, we can understand that the desire to reproduce pleasurable encounters experienced, while sharing others' possessions became a critical factor in becoming providers. Overall, informants' cognizance of the richness of human experience and interactions with others in the CE constitutes a meaningful switchover driver.

Experiencing mutuality. Several informants switched over due to the importance that they attribute to the mutualistic essence of collaborative systems. Mutuality can imply a mechanism of reciprocity as fuel for solidarity [54]. Reciprocity is strongly connected with a sense of social debt, central to alternative exchange systems $[54,55]$. Indeed, our informants mentioned, on several occasions, becoming providers as a means to giving back what they received as obtainers. Here are some examples:

"Considering the satisfaction obtained as a user can influence my desire to give this satisfaction to others as a supplier, it could be interesting. As a student with limited resources, I was more into buying than selling, but if there are certain goods that I no longer use, I could sell them to someone who could reuse them." (Gerard)

"What's interesting about the collaborative economy is a change in mindset. As soon as you start using it, you want to continue; you are less braked. I first received things before giving them away. The experience of receiving gifts progressively affected my mentality to give." (Vincent)

"In general, it's everyday eh, you give and you receive all your life. You receive therefore you also give. When I give I don't expect anything in return. There doesn't have to be a relationship." (Naomy)

These informants all expressed the same urge to give back after receiving from the CE. This urge, however, has its roots in different perspectives. For Gerard, it was the desire to propagate his sense of satisfaction to others. Vincent, on the other hand, referred to a growing sense of needing to reciprocate after multiple experiences of being a receiver:

"The two behaviors are linked: when we see people doing something, we say to ourselves why not us too. It is a cyclical process; when we receive something, we have too much of it suddenly, so we must give some. If we receive, when we receive, it creates the desire to give, it is rewarding and satisfying, and the feeling of recognition that can be triggered in the other is rewarding." (Vincent)

Finally, Naomy expressed her belief in a pearl of folk wisdom associated with giving (if you give, you shall receive) and feels prone to give after receiving so much.

Experiencing peer influence. Peer influence refers to various socialization processes derived from sociological theories [56]. Specifically, peer influence tends to occur predominantly via social interactions [57]. The learners tend to be mainly influenced by others. Our informants occasionally mentioned that their switch to become providers came from being affected by people from their social circles. For example, Pierre expressed how others' promotion of selling incited him to follow:

"I began by buying on platforms, and I heard some friends saying it is very easy to sell too, so I said 'ok, if they succeed, why not me, that is how I became a seller too." (Pierre) 
More specifically, it is by observing others as providers that users may assess the trustworthiness of the act of providing. As stated by Adel:

"I started by buying. However, I also saw that resale was functioning because people I know were getting rid of their belongings without a problem, so surely, I could too. For that reason, I sold what I didn't need. I resold on the same site because I trusted it, and it is a very good site." (Adel)

Pierre and Adel's cases show that witnessing how friends can easily and uneventfully sell items became a factor in adopting the provider role after being first obtainers. A certain additional level of reassurance from peers, which did not seem to matter when acquiring things, may be needed to become sellers.

\subsection{Inhibitors of Switchover}

Inhibitors were strongly expressed in the context of resource mutualization (e.g., care sharing, Couchsurfing, Airbnb, lending, or renting objects). In the context of residence sharing, informants generally manifested hesitation. As Oliver mentioned, "precautions would be needed" because it is "easier to rent someone else's place than offer the service myself." One of the reasons for this hesitation is because one must deal with strangers. In that regard, Pierre mentioned that it would be "reassuring to know what kind of people I would be welcoming in my home." Informants also expressed the risk of personal objects being stolen by strangers who rent the place, as Kevin mentioned: "It's a matter of trust because I don't really know who will come and that person may take away my stuff I don't know. ( ... ) We have to evaluate the risks." Distrusting strangers can therefore be an essential inhibitor. These results align with some past findings, for example, past studies [2] that identified trust as a critical mediator between interchangeability perceptions and participation in the CE.

Moreover, our findings indicate that lack of trust will endanger the "interchangeable" feature of CE by inhibiting the user-provider switch. Since interchangeability influences trust via social proximity [2], it follows that lack of trust could result from a weak perception of interchangeability in the $\mathrm{CE}$ and an inadequate perception of social proximity. Several other types of research emphasized the crucial role of trust (toward the user, the platform, or the overall community) to participate as a provider [49] or to switch from non-user to user [37]. We extend those past studies by showing that distrust hinders the switch from user to provider, further validating the high relevance of trust in CC-based exchanges $[41,58,59]$.

The sense of personal intimacy was also identified as a significant deterrent. A house is seen as highly personal, and the prospect of accepting strangers leads to hesitations to provide. In this regard, Elody mentioned that it is "difficult to see people in my personal space." Naomy added that "if it were a little less personal, it would be fine." Furthermore, there was a perceived risk that a stranger could damage valued personal objects. Erika summarizes this idea:

"No, I will not do it because it's really personal. But if it becomes less useful, I could temporarily put it in a rental for money, and even here, there is a risk to see this item coming back messily. I like having control over my stuff, and I'm not sure that the person to whom I'm renting my things will take care of it like me." (Erika)

This perception of risk as a deterrent to switching to provider echoes Albinsson et al.,'s [37] suggestion that risk-seekers will be more likely to switch from users to non-users. Our findings indirectly suggest that risk-seekers might have fewer inhibitions to switch from user to provider.

Lack of resources can be another deterrent. In the context of car-sharing, lack of car ownership and/or driver's license was mentioned as an important limitation to switch to the supplier. For instance, Sylvestre said: "I started by getting in other people's car only because I did not have my own car and my driver's license."

A final element was the need for skills, like a good sense of organization, which is perceived as lacking by some informants, like Kevin: "I could offer rides if I managed 
to get better organized". In contrast to the externally oriented distrust of strangers, the perceived lack of skills could refer to an internally oriented distrust in oneself.

\section{Discussion of the Results}

\subsection{Personal Values}

The values identified by Albinsson et al. [37] to explain the switch from CE nonuser to user largely overlap with those found in this study, namely, cultural dimensions, sustainability, and materialism. However, we detected utilitarianism instead of materialism and singled out family values from cultural ones.

The prevalence of utilitarian values instead of materialistic in explaining the switch from user to provider is an interesting facet of the study. Materialism conflates with possessiveness, non-generosity, and envy [60], which squarely fits with the act of "using" as an ego-centric means to possess/access, for oneself, a resource to fulfill some sense of envy. In contrast, the switch to the provision is triggered by a broader set of "utilitarian" motives that surpass and even contradict those materialistic dimensions. In line with past research, we found that those utilitarian values encompass profit-making and decluttering, circumventing the burden of ownership, or easily getting rid of things [34-37]. Even for such utilitarian purposes, provision satisfies others' needs, contradicting therefore the materialistic dimension of possessiveness, because (even in commercial exchanges), providers share or transfer some resource to users. This contradiction with materialism is even more pronounced for non-commercial exchanges by opposing more evidently envy and non-generosity. Thus, those results illuminate past findings showing that switching from non-user to user is driven by materialism or, in other words, that the consumption-like act of using is driven by materialism [37]. In contrast, the switch from user to the provider is again driven by a broader nexus of motives that are utilitarian but appear to conflict with materialism, hence the non-appearance of materialistic motives in our findings.

Furthermore, and related to the previous point, whereas users are driven mainly by utilitarian (materialistic) and economic motives, a broader set of non-utilitarian drivers spur on providers [14,31-35], such as waste avoidance [36,38], or prosocial motives [31,32,34,35]. Our results match those findings closely about provider motives by singling out the sustainability ethos conflating with waste avoidance and pinpointing altruistic motives as an overlap with the prosocial ones. We do not find substantial evidence for emotional motives [39] or variety seeking [35]. Thus, we conclude that utilitarianism, altruism, and family values appear as the essential values in explaining the switchover process.

Besides, we complement past research $[37,61]$ on the role of cultural values to explain collaborative behaviors by showing the importance of family values instead of cultural ones in the switchover process. It is worth mentioning that these studies did not focus on the switchover process per se and instead assessed how collaborative behaviors vary across cultures. Nonetheless, it is also interesting to note that a hierarchy of values almost similar to Albinsson et al. [37] governs both types of switches (i.e., from non-user to user; and from user to provider).

\subsection{Learning to Switch}

Learning is a variable that appears unique to switchover, since no other study about provider motives identified it as a motivator. Therefore, it might be reasonably stated that learning is a pivotal and unique factor in a user-provider switch. First, we found that overall buying (using) is more accessible than selling (providing), especially since provision requires resources to mutualize or redistribute, but necessitates that those resources are sought by the market and are in good condition, two conditions that are often difficult to match. This has also been echoed in past research that showed how buying secondhand is more pronounced than reselling [62]. More generally, the acquisition of secondhand goods (via secondhand purchases, receiving items for free, or renting) is also more frequent than providing (reselling, giving away, and lending) [63]. An exception to this "rule" occurs 
when consumers buy "with the intention to resell" [36] (p. 12) or with the "resale value in mind" [64] (p. 549).

Secondly, using first can be seen by some as a way to learn to become a provider. In their study on online planned resale intentions, Chu and Liao [65] demonstrated, in an online setting, how buying to resell (i.e., resell intentions) was more pronounced for individuals who had higher resale possibilities and better external resale prices. Yet, those resale possibilities and resale prices do not exist in a vacuum, as they are known to the potential reseller. Such knowledge might come with increased frequentation and usage of online secondhand channels. By extrapolating to the whole of the $\mathrm{CE}$, which has a significant share online, it is fair to say that the increased use of collaborative exchange schemes will increase the users' knowledge of the potential supply channels, corresponding prices, and mode of functioning, which in turn increases their likelihood "to use to provide", or to provide at a later point.

\subsection{Experiencing the Social Dimension of the Collaborative Economy}

Experiencing the social dimension of the $\mathrm{CE}$ is another variable that appears unique to the switchover process. In contrast to past literature, we show that being an obtainer might sometimes be needed to develop a first-hand experience of the social benefits and positive aspects of using, which will trigger a desire to reciprocate. In other words, if individuals have not experienced the sociability of collaborative exchanges, they may not realize this and may not necessarily desire to reciprocate. We identify three facets to this experience of the social dimension of the CE.

Experiencing social benefits. The first one refers to the experience of social benefits derived from interacting with a community. For instance, the community-building aspect can be very vivid in many commercial and non-commercial collaborative exchange systems.

Past research emphasized that community building was more substantial in collaborative settings where individuals interact physically with resources and others. For example, due to the physicality and scarcity of shared resources between users and the limited physical space, toy libraries are the right settings to different model conceptualizations of citizenship and inculcate them, especially to children [32]. Research on the benefits of time-banking echoes how participating in physical collaborative schemes provides a well-rounded experience to its participants in the form of social, cultural, physical, or human capital [31]. Accordingly, the facet of experiencing social benefits was mainly noticed in mutualization practices, such as sharing a car or a house. In fact, in such instances, both parties (i.e., users and providers) share similar resources, are physically close, and need to interact to coordinate collaborative consumption. Through these collaborations, individuals experience sociality that appears less pronounced in tech-mediated CC, such as reselling, giving away, or swapping things with distant others.

Experiencing mutuality. The importance attributed to social debt and to reciprocate is consistent with past research findings on the CE. For example, while monetary incentives constitute the primary motivation for renting goods to others, the provision might also occur in response to a sense of reciprocity [33,34]. Reciprocal sidedness ranges on a continuum from "generalized reciprocity", determined by disinterestedness (giving without expecting anything in return), personal mutuality, and compassion; to "negative reciprocity", characterized by self-interestedness and in consideration of others [66]. Besides, negative reciprocity is more likely to emerge in "pseudo-sharing" (i.e., commercial exchange masqueraded as sharing [67]), such as car-sharing schemes (e.g., Zipcar) [24]. Generalized reciprocity is more likely to emerge in genuine sharing, such as swapping or renting [33,34] and donating [45].

When collaborative exchanges involve money, this can be referred to as "balanced reciprocity" [68], where an exchange is being governed by a valid and fair market value defined jointly by provider and user [33]. Be it for money or not, a sense of moral obligation caused by a feeling of social debt triggers a desire to reciprocate, in a generalized or balanced fashion, by becoming a provider. 
Experiencing peer influence. While our findings of personal values (i.e., cultural, sustainability, materialism) match past results [37], the sociality dimension that we identified seems especially unique to the user-provider switch, with no less than three variables about sociality (i.e., social benefits, mutuality, peer influence). Social motives were also identified as drivers of provider roles [31,32,34,35]; this research, however, finds that peer influence particularly stands out in the user-provider switch. This may be explicable because peer influence is vital for conventional purchases, luxuries, and socially conspicuous purchases [69]. Being a provider requires effort, a higher level of involvement than the obtaining role, and is likely to be socially visible, explaining the salience of peer influence.

\section{Theoretical Implications}

This study contributes to the CE literature by outlining the switchover process from obtainer to provider. First, our conceptualization of switchover constitutes a unique theoretical contribution to the ongoing discussion on the user and provider motives [37]. Second, we advance the following definition of switchover in the CE setting: switchover is a reversible role transition process through which an obtainer (a provider) becomes a provider (an obtainer). In that sense, switchover refers to the user-to-provider path encapsulated in the broader concept of "interchangeability" [2]. As such, the study characterizes scientifically the phenomenon of obtainers turning into providers, which has been amply discussed in the CE literature and related research streams $[9,70,71]$, under the terms "collaborative consumer networks" [71] (p. 180), "collaborative networks" [9] (p. 152), "lateral exchange markets" [53] (p. 20), or even "crowd-based capitalism" [72].

Furthermore, we extend the literature on provider motives and characterization by identifying three factors that explain the transition from user to provider (see Figure 1). These three factors refer to personal values, learning to switch, and the social dimension of the CE. Personal values encompass altruistic motives, sustainable ethos, and utilitarianism. Learning to switch refers to gaining confidence in the system, gaining self-confidence, and developing expertise. The social dimension related to $\mathrm{CE}$ is the richest in terms of constitutive sub-dimensions, which tells us about the importance of sociality in triggering the switchover process. Sociability relates to social benefits (i.e., desiring to benefit from the presence of others), experiencing mutuality (i.e., wanting to reciprocate what was given/obtained in previous collaborative exchanges and to make others experience positive states), and peer influence (i.e., following others' suggestions or observing other's experiences). Meanwhile, the study goes further by identifying potential inhibitors to the switchover process. Those hindrances include distrust in strangers, personal intimacy, lack of resources to share, and lack of skills.

When comparing those emerging themes with past findings, it is interesting to see that some factors overlap with provider motivations found in extant research. At the same time, we also identify unique sets of specific variables to the user-provider switch. More specifically, personal values (i.e., altruism, sustainability, utilitarianism), social benefits, mutuality, and (dis)trust overlap with provider factors [2,31-35]. In contrast, learning, peer influence, sense of intimacy (to some extent), lack of resources to share, and lack of skills appear unique to the switchover process. The identification of several unique inhibitors, in addition to distrust, may better explain the difficulty for the switchover to occur.

\section{Managerial Implications}

For managers and professionals, strategies aimed at converting users into providers should focus on sociability. Social benefits of exchanging with others and joining a community of peers could be coupled with mechanisms exposing users to testimonies of those who switched to providers. An ideal place to deploy such a strategy would be social media, where peers' influence and desire to follow social norms are relatively strong. Managers could also trigger social debt feelings (i.e., mutuality) by emphasizing the positive feelings that arise when giving back to others, to the community, as a provider. The operation of the exchange system should be made as easy as possible to expedite users' learning curve to 
provide. The use of independent third-party systems can foster trust. This is especially true for online review comments that provide most of the information used to form judgments about users, providers, the platform, or the community at large [58]. Most platforms use proprietary systems that may be unrealistically positive, such as eBay [73]. Independent providers like Trust Pilot, for example, manage the review process independently, which fosters trust. Overcoming a sense of intimacy, lack of resources and skills depends on the sector of the platform. Still, it might be good for platforms to extend their breadth by allowing a broader range of products and resources to be exchanged, including fewer intimate ones. In a few easy steps, users avoid becoming restrained by a perceived lack of resources to exchange or lack skills.

\section{Limitations and Future Research Avenues}

Limitations to the current study suggest potentially interesting avenues for future research. First, the study over-represents the informants from the millennial group. Thus, caution should be taken in extrapolating the findings to other generational cohorts. Second, we take a general view on the $\mathrm{CE}$, although it encompasses diverse structures (e.g., nonprofit to highly commercial ones). Future research could focus more on specific areas within the vaster CE ensemble. We identified two inhibitors to switchover in the CE. Future research should further pursue how consumers trade-off drivers of switchover with these inhibitors. A second avenue could be to study how managers can specifically target consumers who are already participating in the $C E$ yet are reluctant to expand their involvement due to such inhibitors.

Finally, the qualitative research design adopted in this study provided rich insights into the key factors that enter into play to spur or inhibit switchover. Yet, this approach does not quantify the magnitude of each factor in the model. It could well be that some inhibiting factors such as distrust, for example, exert such a high influence on the overall behavior that the switch will never occur despite the high-albeit comparatively lower-levels of values, learning how to switch and experience with the social dimension of $\mathrm{CE}$, altogether. While factor types and their directionality have inductively emerged in this study, the magnitude and the interplay between factors remain yet to be uncovered, especially in diverse CE systems, exchange types, and for specific products or services exchanged.

Author Contributions: Conceptualization, M.E. and E.S.; Data curation, M.E.; Formal analysis, M.E. and J.D.; Funding acquisition, M.E. and E.S.; Investigation, M.E. and J.D.; Methodology, M.E.; Project administration, M.E.; Resources, M.E.; Supervision, E.S.; Validation, J.D. and E.S.; Visualization, J.D. and E.S.; Writing-original draft, M.E.-review \& editing, J.D. and E.S. All authors have read and agreed to the published version of the manuscript.

Institutional Review Board Statement: Not applicable.

Informed Consent Statement: Not applicable.

Data Availability Statement: Not applicable.

Funding: This research was funded by the Social Sciences and Humanities Research Council (SSHRC) of Canada, grant number: 430-2018-00415. The authors are very grateful to SSHRC for their financial support in conducting this research.

Acknowledgments: The authors are thankful to the department of administrative sciences of the University of Quebec in Chicoutimi for the administrative and technical support that enabled the conduct of this research.

Conflicts of Interest: The authors declare no conflict of interest. The funder had no role in the design of the study; in the collection, analyses, or interpretation of data; in the writing of the manuscript, or in the decision to publish the results. 


\section{Appendix A}

Table A1. Additional data about the factors as perceived by the respondents.

\begin{tabular}{ll}
\hline Switchover Factors & Illustrations \\
\hline Drivers &
\end{tabular}

- "My mother told me that if I wanted to buy new clothes, I had to sell or give some of them." (Martine) - "Also I have a strong opinion about ecology and dislike the fact of buying something that we won't ever use and as such, overconsuming. So, I changed my mind about my possessions and am ready to live with 1. Personal values less of them." (Helen)

- "I use car-sharing because we have to save the planet. Why should we use so many cars when we can use just one for our transportation needs?" (Naomy)

- "I found it less interesting to throw it away, so I recycled it." (Fabien)

- "As a receiver, I saw how donations work, so I thought why not donate as well?" (Martine)

- "And also the fact I have used car sharing before and I decided to offer it." (Sylvestre)

- "It was like a sign of trust because I never had problems when I bought on this website, so I didn't hesitate to use the same website to resell on it too." (Naomy)

2. Learning - "I searched for information on this app just to comfort me before using it. The first time just for trying and then other times because I got a good service." (Fabien)

- "First of all, it was a need. After that, I saw that it is trustful, and it runs well. I need to be assured that it is trustful before getting in." (Fabiola)

- "It's this website that I trust the most because I've heard a lot about it from my peers who had already used it." (Sylvestre)

- "My father used to buy on this website, and so I trusted this website for my purchases." (Helen)-

3. Peer influence

"Whatever the good is, anyone can find something which can give him happiness. My friends, my entourage and their experience convinced me to try." (Fabien)

- "Online everywhere, more flexible and practical. My friend said a lot about it and recommended me to try." (Fabiola)

- "In fact, it's a win-win partnership, it's good for the recipients, and it makes for a turnover in the donor's business." (Françoise)

- " ... There is also interaction, meeting people, making connections. The first time, it was nice, well spent as a user, so I also wanted to offer it." (Martine)

4. Social benefits

- "I used carpooling for the first time as a passenger, and I find the conversation during the trip very interesting and sympathetic, so when I own my car, I choose to propose the carpooling service for some trips because I know that with someone with me in my car, the trip will be less boring." (Armand)

- "The experience as a recipient makes you want to make that happen to other people too." (Françoise)

5. Mutuality

- "I used to share with my siblings. They already gave some stuff to me, so it is natural for me to give too." (Sylvestre)

- "I can't use Airbnb because I have a lot of personal stuff. Besides, when I face unknown situations, I don't trust. Maybe later, but not now. ( . . . ) "It's hard to give my stuff to someone that I don't know. In front of a lambda person, I cannot lend my personal stuff." (Naomy)

- "To start as a user because it is easier to get into someone else's intimacy than to let others in my intimacy."

6. Inhibitors (Nicolas)

-Even if the experience went well as a tenant, it would be difficult [as a renter] in the sense that it is about my personal things, my privacy." (John)

- "I would find it hard to lend something to someone that I don't know. I'm not this type of guy who can easily trust someone else." (Sylvestre)

\section{References}

1. Ertz, M.; Durif, F.; Arcand, M. Collaborative Consumption: Conceptual Snapshot at a Buzzword. SSRN Electron. J. 2016, 19, 1-25. [CrossRef]

2. Nguyen, S.; Alaoui, M.D.; Llosa, S. When interchangeability between providers and users makes a difference: The mediating role of social proximity in collaborative services. J. Bus. Res. 2020, 121, 506-515. [CrossRef]

3. Ertz, M.; Lecompte, A.; Durif, F. Dual Roles of Consumers: Towards an Insight into Collaborative Consumption Motives. Int. J. Mark. Res. 2017, 59, 725-748. [CrossRef] 
4. Ertz, M.; Durif, F.; Arcand, M. A conceptual perspective on collaborative consumption. AMS Rev. 2019, 9, 27-41. [CrossRef]

5. Kumar, V.; Lahiri, A.; Dogan, O.B. A strategic framework for a profitable business model in the sharing economy. Ind. Mark. Manag. 2018, 69, 147-160. [CrossRef]

6. $\quad$ Eckhardt, G.M.; Houston, M.B.; Jiang, B.; Lamberton, C.; Rindfleisch, A.; Zervas, G. Marketing in the Sharing Economy. J. Mark. 2019, 83, 5-27. [CrossRef]

7. Curtis, S.K.; Mont, O. Sharing economy business models for sustainability. J. Clean. Prod. 2020, 266, 121519. [CrossRef]

8. Cambridge Dictionary. 2020. Available online: https://dictionary.cambridge.org/fr/dictionnaire/anglais/switch-over (accessed on 20 March 2020).

9. Scaraboto, D. Selling, Sharing, and Everything in between: The Hybrid Economies of Collaborative Networks. J. Consum. Res. 2015, 42, 152-176. [CrossRef]

10. Tomasello, M. Why We Cooperate; MIT Press: Cambridge, MA, USA, 2009.

11. Botsman, R.; Rogers, R. What's Mine Is Yours; Penguin Press: New York, NY, USA, 2010.

12. Doubek, J. Google Has Received 650,000 Right to Be Forgotten Requests since 2014. Available online: https:/ / www.npr.org/ sections / thetwo-way /2018/02/28/589411543/google-received-650-000-right-to-be-forgotten-requests-since-2014 (accessed on 18 May 2021).

13. PYMNTS. Uber, Lyft Struggle to Keep Drivers on Board. PYMNTS. 12 May 2019. Available online: https://www.pymnts.com/ news / ridesharing/2019/uber-lyft-drivers / (accessed on 26 March 2021).

14. Bucher, E.; Fieseler, C.; Lutz, C. What's mine is yours (for a nominal fee)—Exploring the spectrum of utilitarian to altruistic motives for Internet-mediated sharing. Comput. Hum. Behav. 2016, 62, 316-326. [CrossRef]

15. Efrati, A. How Uber Will Combat Rising Driver Churn. The Information, 20 April 2017. Available online: https://www. theinformation.com/articles/how-uber-will-combat-rising-driver-churn (accessed on 26 March 2021).

16. Tomslee. The shape of Airbnb's Business. Tom Slee, 26 May 2014. Available online: http://tomslee.net/2014/05/the-shape-ofairbnbs-business.html (accessed on 26 March 2021).

17. Chu, J.; Manchanda, P. Quantifying Cross and Direct Network Effects in Online Consumer-to-Consumer Platforms. Mark. Sci. 2016, 35, 870-893. [CrossRef]

18. INFORMS. Sellers 3.5 Times More Influential Than Buyers in Driving the Growth of E-Commerce Platforms; New Study Finds. Catonsville, MD, USA, 2016. Available online: https://www.informs.org/About-INFORMS/News-Room/Press-Releases/ Sellers-3.5-times-more-influential-than-buyers-in-driving-the-growth-of-e-commerce-platforms (accessed on $18 \mathrm{May} 2021$ ).

19. Zeithaml, V.A.; Bitner, M.J.; Gremler, D.D. Services Marketing: Integrating Customer Focus across the Firm, 7th ed.; Mc-Graw-Hill: New York, NY, USA, 2018.

20. Gallo, A. The Value of Keeping the Right Customers. Harvard Business Review, 29 October 2014. Available online: https: / /hbr.org/2014/10/the-value-of-keeping-the-right-customers\# (accessed on 14 May 2021).

21. Reichheld, F. Prescription for Cutting Costs: Loyal Relationships; Bain and Company, Inc.: Boston, MA, USA, 2019.

22. Leismann, K.; Schmitt, M.; Rohn, H.; Baedeker, C. Collaborative consumption: Towards a resource-saving consumption culture. Resources 2013, 2, 184. [CrossRef]

23. Chung, E. Millennial's Mobile Tech Savvy Leaves Boomers Behind. CBC, 3 December 2013. Available online: https: //www.cbc.ca/news/science/millennials-mobile-tech-savvy-leaves-boomers-behind-1.2449252\#: \{\}:text=Canadian\%20 adults\%20aged\%2033\%20and,networking\%2C\%20a\%20new\%20survey\%20indicates (accessed on 14 May 2021).

24. Bardhi, F.; Eckhardt, G.M. Access-Based Consumption: The Case of Car Sharing: Table 1. J. Consum. Res. 2012, 39, 881-898. [CrossRef]

25. Ertz, M.; Lecompte, A.; Durif, F. It's not my fault, I am in the right! Exploration of neutralization in the justification of the support and use of a controversial technological collaborative consumption service. Technol. Forecast. Soc. Chang. 2018, 134, 254-264. [CrossRef]

26. Price, M. Fashion Disruptors: Welcome to the Era of Secondhand Retail Apps. CENT, 28 October 2019. Available online: https: //www.cnet.com/features / rise-of-secondhand-retail-poshmark-thredup-letgo-mercari-ebay-thrift-clothing-selling-apps / (accessed on 14 May 2021).

27. Armstrong Soule, C.A.; Hanson, S. An overview, framework and research propositions of secondhand exchange in the platform economy. In Handbook of Research on the Platform Economy and the Evolution of E-Commerce; Ertz, M., Ed.; IGI Global: Hershey, PA, USA, forthcoming.

28. Armstrong Soule, C.A.; Hanson, S. Buying unicorns: The impact of consumer-to-consumer branded buy/sell/trade communities on traditional retail buying behavior. J. Assoc. Consum. Res. 2018, 3, 260-276. [CrossRef]

29. Gansky, L. The Mesh: Why the Future of Business Is Sharing; Penguin Press: New York, NY, USA, 2010.

30. Giesler, M. Consumer gift systems. J. Consum. Res. 2006, 33, 283-290. [CrossRef]

31. Ozanne, L.K. Learning to exchange time: Benefits and obstacles to time banking. Int. J. Community Curr. Res. 2010, 14, A1-A16.

32. Ozanne, L.K.; Ozanne, J.L. A Child's Right to Play: The Social Construction of Civic Virtues in Toy Libraries. J. Public Policy Mark. 2011, 30, 264-278. [CrossRef]

33. Philip, H.E.; Ozanne, L.K.; Ballantine, P. Examining temporary disposition and acquisition in peer-to-peer renting. J. Mark. Manag. 2015, 31, 1310-1332. [CrossRef] 
34. Philip, H.E.; Ozanne, L.K.; Ballantine, P.W. The rise and fall of peer-to-peer collaborative consumption: A perspective from two types of collaborative consumption practices. In The Rise of the Sharing Economy: Exploring the Challenges and Opportunities of Collaborative Consumption; Albinsson, P.A., Perera, B.Y., Eds.; Praeger: Santa Barbara, CA, USA, 2018; pp. 159-182.

35. Philip, H.E.; Ozanne, L.K.; Ballantine, P.W. Exploring online peer-to-peer swapping: A social practice theory of online swapping. J. Mark. Theory Pract. 2019, 27, 413-429. [CrossRef]

36. Chu, H.; Liao, S. Exploring consumer resale behavior in $\mathrm{C} 2 \mathrm{C}$ online auctions: Taxonomy and influences on consumer decisions. Acad. Mark. Sci. Rev. 2007, 11, 1-27.

37. Albinsson, P.A.; Perera, B.Y.; Nafees, L.; Burman, B. Collaborative consumption usage in the US and India: An exploratory study. J. Mark. Theory Pract. 2019, 27, 390-412. [CrossRef]

38. Okada, E.M. Trade-ins, Mental Accounting, and Product Replacement Decisions. J. Consum. Res. 2001, 27, 433-446. [CrossRef]

39. Herrmann, G.M.; Soiffer, S.M. For fun and profit: An analysis of the American garage sale. Urban Life 1984, 12, 397-421. [CrossRef]

40. Albinsson, P.A.; Perera, B.Y. Alternative marketplaces in the 21st century: Building community through sharing events. J. Consum. Behav. 2012, 11, 303-315. [CrossRef]

41. Hawlitschek, F.; Teubner, T.; Gimpel, H. Consumer motives for peer-to-peer sharing. J. Clean. Prod. 2018, 204, 144-157. [CrossRef]

42. Albinsson, P.A.; Perera, B.Y. Access-based consumption: From ownership to non-ownership of clothing. In The Rise of the Sharing Economy: Exploring the Challenges and Opportunities of Collaborative Consumption; Albinsson, P.A., Perera, B.Y., Eds.; Praeger: Santa Barbara, CA, USA, 2018; pp. 183-212.

43. Albinsson, P.A.; Perera, B.Y. From trash to treasure and beyond: the meaning of voluntary disposition. J. Consum. Behav. 2009, 8 , 340-353. [CrossRef]

44. Gupta, M.; Esmaeilzadeh, P.; Uz, I.; Tennant, V.M. The effects of national cultural values on individuals' intention to participate in peer-to-peer sharing economy. J. Bus. Res. 2019, 97, 20-29. [CrossRef]

45. Price, L.L.; Arnould, E.J.; Curasi, C.F. Older Consumers' Disposition of Special Possessions. J. Consum. Res. 2000, $27,179-201$. [CrossRef]

46. Corbin, J.; Strauss, A. Basics of Qualitative Research: Techniques and Procedures for Developing Grounded Theory; SAGE: Thousand Oaks, CA, USA, 2008.

47. Hwang, J.; Griffiths, M.A. Share more, drive less: Millennials value perception and behavioral intent in using collaborative consumption services. J. Consum. Mark. 2017, 34, 132-146. [CrossRef]

48. Patton, M.Q. Qualitative Research and Evaluation Methods; SAGE: Thousand Oaks, CA, USA, 2002.

49. Fortin, M.F.; Gagnon, J. Fondements et Étapes du Processus de Recherche: Méthodes Quantitatives et Qualitatives; Chenelière Éducation: Quebec City, QC, Canada, 2016.

50. Braun, V.; Clarke, V. Using thematic analysis in psychology. Qual. Res. Psychol. 2006, 3, 77-101. [CrossRef]

51. Dolan, P.; Galizzi, M.M. Like ripples on a pond: Behavioral spillovers and their implications for research and policy. J. Econ. Psychol. 2015, 47, 1-16. [CrossRef]

52. Belk, R. Sharing. J. Consum. Res. 2010, 36, 715-734. [CrossRef]

53. Perren, R.; Kozinets, R.V. Lateral Exchange Markets: How Social Platforms Operate in a Networked Economy. J. Mark. 2018, 82, 20-36. [CrossRef]

54. Arnould, E.J.; Rose, A.S. Mutuality: Critique and substitute for Belk's "sharing". Mark. Theory 2016, 16, 75-99. [CrossRef]

55. Komter, A. Social Solidarity and the Gift; Cambridge University Press: Cambridge, MA, USA, 2005.

56. Riesman, D.; Roseborough, H. Careers and consumer behavior. Consum. Behav. 1955, 2, 1-18.

57. Smith, R.B.; Moschis, G.P.; Moore, R.L. Some advertising influences on the elderly consumer: Implications for theoretical consideration. Curr. Issues Res. Advert. 1985, 8, 187-201.

58. Ter Huurne, M.; Ronteltap, A.; Corten, R.; Buskens, V. Antecedents of trust in the sharing economy: A systematic review. J. Consum. Behav. 2017, 16, 485-498. [CrossRef]

59. Möhlmann, M. Collaborative consumption: Determinants of satisfaction and the likelihood of using a sharing economy option again. J. Consum. Behav. 2015, 14, 193-207. [CrossRef]

60. Belk, R. Three scales to measure constructs related to materialism: Reliability, validity, and relationships to measures of happiness. ACR N. Am. Adv. 1984, 11, 291-297.

61. Davidson, A.; Habibi, M.R.; Laroche, M. Materialism and the sharing economy: A cross-cultural study of American and Indian consumers. J. Bus. Res. 2018, 82, 364-372. [CrossRef]

62. Lane, R.; Horne, R.; Bicknell, J. Routes of reuse of second-hand goods in Melbourne households. Aust. Geogr. 2009, 40, 151-168. [CrossRef]

63. Brauer, C.N. A Panoramic Image-based Approach to Buying and Selling Secondhand Goods Online. Ph.D. Thesis, Purdue University Graduate School, West Lafayette, IN, USA, 2019.

64. Turunen, L.L.M.; Pöyry, E. Shopping with the resale value in mind: A study on secondhand luxury consumers. Int. J. Consum. Stud. 2019, 43, 549-556. [CrossRef]

65. Chu, H.; Liao, S. Buying while expecting to sell: The economic psychology of online resale. J. Bus. Res. 2010, 63, 1073-1078. [CrossRef]

66. Sahlins, M. Stone Age Economics; Aldine Atherton: Chicago, IL, USA, 1972.

67. Belk, R. You are what you can access: Sharing and collaborative consumption online. J. Bus. Res. 2014, 67, 1595-1600. [CrossRef] 
68. Bagozzi, R.P. Social exchange in marketing. J. Acad. Mark. Sci. 1975, 3, 314-327. [CrossRef]

69. Bearden, W.O.; Rose, R.L.; Teel, J.E. Correlates of conformity in the consumption of illicit drugs and alcohol. J. Bus. Res. 1994, 30, 25-31. [CrossRef]

70. Corciolani, M.; Dalli, D. Gift-giving, sharing and commodity exchange at Bookcrossing. com: New insights from a qualitative analysis. Manag. Decis. 2014, 52, 755-776.

71. Scaraboto, D.; Figueiredo, B. Holy Mary goes' round: Using object circulation to promote hybrid value regimes in alternative economies. J. Macromark. 2017, 37, 180-192. [CrossRef]

72. Sundararajan, A. The Sharing Economy: The End of Employment and the Rise of Crowd-Based Capitalism; MIT Press: Cambridge, MA, USA, 2017.

73. Rietjens, B. Trust and reputation on eBay: Towards a legal framework for feedback intermediaries. Inf. Commun. Technol. Law 2006, 15, 55-78. [CrossRef] 